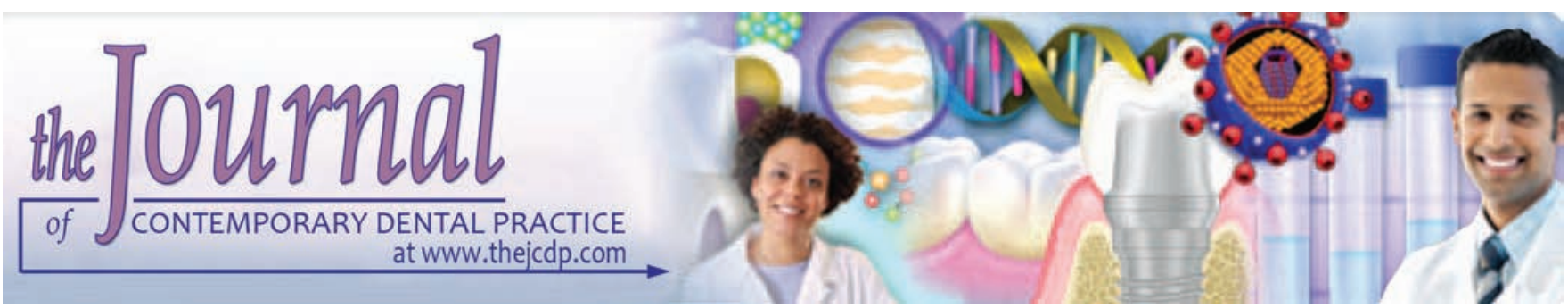

\title{
Evaluation of Inflammatory Response to Endodontic Sealers in a Bone Defect Animal Model
}

\author{
${ }^{1}$ Miriam Z Scelza, ${ }^{2}$ Carlos AM Campos, ${ }^{3}$ Pantaleo Scelza, ${ }^{4}$ Caroline SR Adeodato, ${ }^{5}$ Igor B Barbosa \\ ${ }^{6}$ Fernando de Noronha, ${ }^{7}$ Victor Montalli, ${ }^{8}$ Marcelo Napimoga, ${ }^{9}$ Vera C de Araújo, ${ }^{10}$ Gutemberg G Alves
}

\begin{abstract}
Aim: The aim of this study was to evaluate the inflammatory response to MTA Fillapex, AH Plus, and Pulp Canal Sealer Extensive Work Time (EWT), in a murine bone defect grafting model.
\end{abstract}

Materials and methods: Bilateral mandibular critical defects were produced in 45 Wistar rats with a trephine bur\#2 and filled with the endodontic sealers. After 7, 14, and 28 days, the rats were euthanized and their jaws were histologically prepared.

Results: For the 7-day group, no statistical significance was observed among all studied groups ( $p>0.05)$, and high levels of inflammatory infiltrate were detected. After 14 and 28 days, Pulp Canal Sealer EWT showed statistically lower inflammatory response in comparison to other sealers $(p<0.05)$ except for the control group (no sealers).

Conclusion: Pulp Canal Sealer EWT presented the lowest levels of inflammatory response. The critical defect grafting model was an effective method to detect differences among differences on the biological response to endodontic sealers.

Clinical significance: Knowing the biocompatibility of endodontics sealers that will be used in filling the root canal.

\footnotetext{
1,3,6 Department of Endodontics, Fluminense Federal University, Niterói, Rio de Janeiro, Brazil

${ }^{2}$ Department of Immunobiology, Fluminense Federal University, Niterói, Rio de Janeiro, Brazil

${ }^{4,5}$ Department of Dentistry, Fluminense Federal University Niterói, Rio de Janeiro, Brazil

${ }^{7-9}$ Laboratory of Oral Pathology and Immunology and Molecular Biology, São Leopoldo Mandic, Campinas, São Paulo, Brazil

${ }^{10}$ Department of Molecular and Cell Biology, Institute of Biology, Fluminense Federal University, Niterói, Rio de Janeiro Brazil

Corresponding Author: Miriam Z Scelza, Professor Department of Endodontics, Fluminense Federal University, Niteroi, Rio de Janeiro, Brazil, Phone: +552199840270 e-mail: scelza@terra.com.br
}

Keywords: Animal experimentation, Biocompatibility testing, Endodontics, Inflammation, Materials testing.

How to cite this article: Scelza MZ, Campos CAM, Scelza P, Adeodato CSR, Barbosa IB, de Noronha F, Montalli V, Napimoga M, de Araújo VC, Alves GG. Evaluation of Inflammatory Response to Endodontic Sealers in a Bone Defect Animal Model. J Contemp Dent Pract 2016;17(7):536-541.

Source of support: This research was supported by FAPERJ, under the process no. E-26/110.909/2009.

Conflict of interest: None

\section{INTRODUCTION}

Since gutta-percha cones do not adhere directly to the root canal wall, their application on endodontic filling is often combined to the use of an endodontic sealer. ${ }^{1}$ Nowadays, several different compositions for, such sealers have been already developed and employed with the purpose of achieving more desirable physicochemical properties, as well as improved biocompatibility with periapical tissues. ${ }^{2}$ In this context, root canal sealers may be ordered based on chemical composition in several different groups, such as calcium hydroxides, bioceramics, zinc oxide/eugenol, or epoxy resins.

Endodontic filling materials may be considered true implants, as they remain in direct and intimate contact with vital tissues for considerably longer period of time. ${ }^{3}$ Therefore, regardless of their chemical composition, endodontic sealers should be associated with adequate biological responses, in order to ensure the safety of their clinical use.

The International Organization for Standardization (ISO) states that tissue compatibility evaluation, both in vitro and in vivo, when appropriate, should be carried out as important steps prior to the clinical employment of any material or device. ${ }^{4-6}$

A considerable amount of research effort has been dedicated to the understanding of the biocompatibility 
of root canal sealers, mostly by in vitro approaches and cytotoxicity assays. Several studies were focused on the comparison of cytotoxicity of different sealer groups. Al-Hiyasat et $\mathrm{al}^{2}$ evaluated, through a murine fibroblast model, the materials Epiphany, EndoREZ, Metaseal, and AH Plus, which showed different levels of toxicity. Zhang et $\mathrm{al}^{7}$ reported that the bioceramic sealer EndoSequence BC Sealer was less toxic to L929 mouse fibroblasts when compared to the resin-based AH Plus. In a recent in vitro study, Scelza et $\mathrm{al}^{8}$ described strong levels of cytotoxicity in primary human osteoblasts for several representatives of different sealer groups. Other parameters have also been assessed, such as the capacity of differentiation and mineralization of osteogenic cell lineages in the presence of endodontic sealers. ${ }^{9}$

However, in vitro cytotoxicity assays are usually not able to access all long-term effects of some materials, which might cause a persistent inflammation or foreign body reaction in the periapical tissues and may delay the wound-healing process. ${ }^{10,11}$ Consequently, international standards for material testing recommend the subsequent use of in vivo assays, such as subcutaneous tissue tests. ${ }^{12}$ Nevertheless, data obtained through the subcutaneous approach constitute a model of limited value to represent the periapical region, because there is a lack of mineralization potential and it does not access events, such as movements, which might contribute to local irritation. Other in vivo animal models employing bone tissues may represent promising tools for a better understanding of the initial and long-term biocompatibility of endodontic materials. ${ }^{13}$

Therefore, the aim of this study was to compare the biocompatibility of different endodontic sealers: The bioceramic MTA Fillapex (Angelus, Curitiba, PR, Brazil), the epoxy resin-based AH Plus (Dentsply/Maillefer, Konstanz, Germany), and the zinc oxide/eugenolbased Pulp Canal Sealer Extensive Work Time (EWT) (SybronEndo, Orange, CA, USA) employing an animal grafting model in critical-sized mandibular defects.

\section{MATERIALS AND METHODS}

The present study has been independently reviewed and approved by the Ethical Committee for Animal Experiments of the Fluminense Federal University (00198/09), and followed national guidelines for animal welfare and the care/use of animals for experimental procedures.

Sixty adult Wistar rats (Rattus novergicus Albinus) were included in this study, weighting 180 to $200 \mathrm{gm}$. For surgical procedures, all animals were anesthetized intraperitoneally with ketamine hydrochloride (Ketalar; Pfizer, São Paulo, Brazil) at a dosage of $0.2 \mathrm{~mL} / 100$ gm of body weight, associated with dihydrothiazine hydrochloride
(Rompum; Bayer, Rio de Janeiro, Brazil), at a dosage of $0.05 \mathrm{~mL} / 100 \mathrm{gm}$. To prevent local discomfort, $0.6 \mathrm{~mL}$ of $2 \%$ xylocaine with epinephrine $(1: 100,000)$ was injected in the mucobuccal fold of the mandibular incisors region.

\section{Bone Defect Creation}

The bone defect was induced according to the previous work. ${ }^{13}$ A $20 \mathrm{~mm}$ incision was made in both the right and left sides of the jaw region of each animal after shaving and washing the skin with povidine iodine. A trephine bur \#2 (Incol; Instrumentos Cirúrgicos Oftalmológicos Ltda, São Paulo, Brazil), was used to create a standardized, round, through-and-through osseous defect ( $5 \mathrm{~mm}$ in diameter) on both sides of the jaw. The defects size is consistent with a so-called critical size defect implying that the defect does not heal spontaneously during the animal's lifetime. ${ }^{14}$

The animals were randomly distributed into three experimental groups ( $\mathrm{n}=15$ animal per group, total $=45$ ). The bone defects were filled with MTA Fillapex, Pulp Canal Sealer EWT, and AH Plus on one side of the lower jaw. All materials were prepared according to the manufacturers' recommendation for their clinical use (Table 1). The sealers were implanted in a freshly mixed, unset state and the opposite side incision was used as a control (blood clot) without the endodontic sealer.

\section{Histological Preparation}

The animals were euthanized with tripled doses of the same anesthetics employed on surgery, on the 7th, 14th, and 28 th day ( $n=5$ per time). The lower jaw was excised, and any excessive tissue was removed. The hemijaws were fixed in $10 \%$ formaldehyde and subsequently decalcified in $20 \%$ formic acid for 21 days. Afterwards, the samples were

Table 1: Constituents of the investigated endodontic sealers

\begin{tabular}{|c|c|c|}
\hline $\begin{array}{l}\text { Product and } \\
\text { manufacturer }\end{array}$ & Composition & $\begin{array}{l}\text { Brief preparation } \\
\text { mode }\end{array}$ \\
\hline $\begin{array}{l}\text { Pulp Canal Sealer } \\
\text { EWT (Sybron } \\
\text { Endo, Orange, } \\
\text { CA, USA) }\end{array}$ & $\begin{array}{l}\text { Powder: Zinc oxide, } \\
\text { silver, resin, liquid, } \\
\text { eugenol, Canada } \\
\text { balsam }\end{array}$ & $\begin{array}{l}\text { The components } \\
\text { are combined } \\
\text { trough a mixing the } \\
\text { powder into liquid. }\end{array}$ \\
\hline $\begin{array}{l}\text { AH Plus } \\
\text { (Dentsply/ } \\
\text { Maillefer, } \\
\text { Konstanz, } \\
\text { Germany) }\end{array}$ & $\begin{array}{l}\text { Epoxy resins, Calcium } \\
\text { tungstate, Zirconium } \\
\text { oxide, aerosol, Iron } \\
\text { oxide, Adamantane } \\
\text { amine, N,N-Dibenzyl- } \\
\text { 5-oxanonane, TCD- } \\
\text { Diamine, Calcium } \\
\text { tungstate, Zirconium } \\
\text { oxide, Aerosil }\end{array}$ & $\begin{array}{l}\text { The components } \\
\text { are combined } \\
\text { trough a mixing of } \\
\text { equal portions by } \\
\text { length of base and } \\
\text { catalyst paste. }\end{array}$ \\
\hline $\begin{array}{l}\text { MTA Fillapex } \\
\text { (Angelus, } \\
\text { Curitiba, PR } \\
\text { Brazil) }\end{array}$ & $\begin{array}{l}\text { Salicylate resin, } \\
\text { diluting resin, natural } \\
\text { resin, bismuth trioxide, } \\
\text { nanoparticulated silica, } \\
\text { MTA, pigments }\end{array}$ & $\begin{array}{l}\text { The components } \\
\text { are combined } \\
\text { trough a self-mixing } \\
\text { tip attached to a } \\
\text { syringe. }\end{array}$ \\
\hline
\end{tabular}


embedded in paraffin, and frontal semi-serial sections of the hemijaws were cut at a thickness of $7 \mu \mathrm{m}$. The sections were then processed for hematoxylin-eosin staining.

\section{Histological Evaluation}

The inflammatory responses were measured by two experienced pathologists, as blind observers previously calibrated to the research setting. Tissue inflammatory response was graded according to previous references, ${ }^{15,16}$ following the score of $0=$ (absence of inflammatory cells), $1=$ light (few inflammatory cells), $2=$ moderate (presence of macrophages and/or plasma cells), and $3=$ severe (focal areas of necrosis; tissue densely infiltrated by inflammatory cells). The histological evaluation and description of the observed tissue response were performed with a light binocular microscope (Zeiss Axioskop 2, Carl Zeiss MicroImaging $\mathrm{GmbH}$, Jena, Germany).

\section{Statistical Analysis}

Comparisons between scores obtained during the histological evaluation were performed using nonparametrical analysis of variance (ANOVA), through the Kruskal-Wallis test, setting the alpha error to $5 \%$. Two-way ANOVA was also applied followed by Bonferroni test in order to analyze the intragroup statistical differences.

\section{RESULTS}

Figure 1 shows the representative histological section for each test group. It is possible to observe that all groups present some level of inflammatory infiltrate by 7 days
(Figs 1A to D), but it has a tendency to disappear on the control group after 14 and 28 days (Figs 1E to L). MTA Fillapex and Pulp Canal Sealer EWT were completely removed during histological processing. It was possible to observe residues of AH Plus on all samples, usually associated with high levels of inflammatory infiltrate.

Graphs 1A to C shows the result of the score-based analysis of the histological images for each group. Over a period of 7 days, all endodontic sealers and the control group showed similar high levels of inflammatory response, without significant statistical difference $(p>0.05)$ (Graph 1A). The inflammatory reaction remained intense for both AH Plus and MTA Fillapex after 14 and 28 days. On the other hand, the Pulp Canal Sealer EWT and control groups showed a significant decrease on inflammatory reaction after 7 days (Graphs 1B and C). Twenty-eight days after surgery, samples from the control group presented virtually no inflammatory response.

Graph 2 presents an intragroup analysis of the inflammatory response over time for each endodontic sealer. The control group statistically decreases the inflammatory response over time $(p<0.05)$ as observed also with the Pulp Canal Sealer $(\mathrm{p}<0.05)$. Both AH Plus and MTA Fillapex maintained elevated inflammatory response during all time periods evaluated $(p>0.05)$.

\section{DISCUSSION}

The development of novel endodontic materials should be accompanied by adequate methodologies for the assessment of their biological responses. The method employed in the present study was previously described
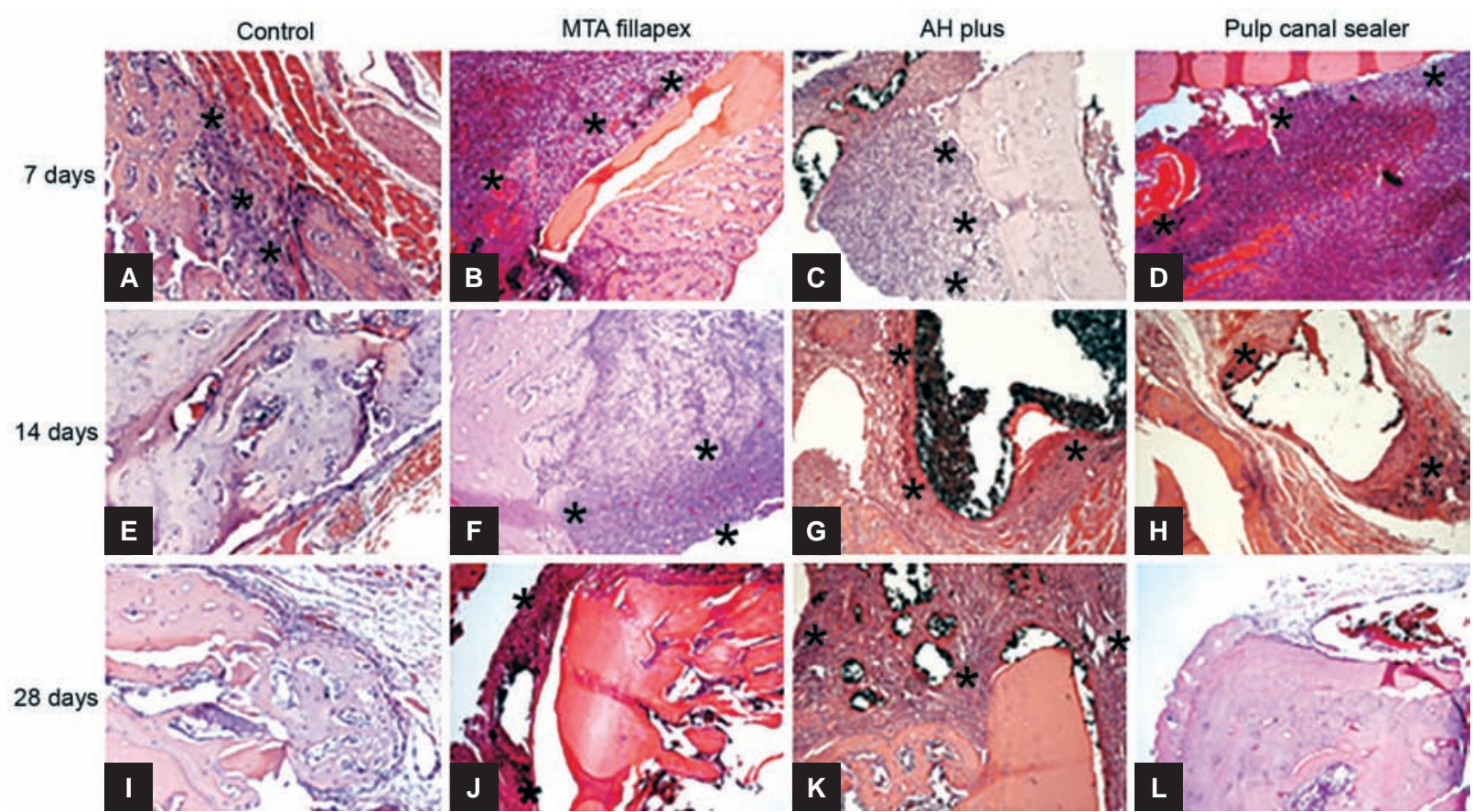

Figs $1 \mathrm{~A}$ to L: Histological images showing the inflammatory infiltrate around the bone defects (indicated by asterisks). Day 7 (A) Control; (B) MTA Fillapex; (C) AH Plus; (D) Pulp Canal Sealer; 14 days (E) Control; (F) MTA Fillapex; (G) AH Plus; (H) Pulp Canal Sealer; 28 days (I) Control; (J) MTA Fillapex; (K) AH Plus; and (L) Pulp Canal Sealer; (H\&E, original magnification $\times 100)$ 

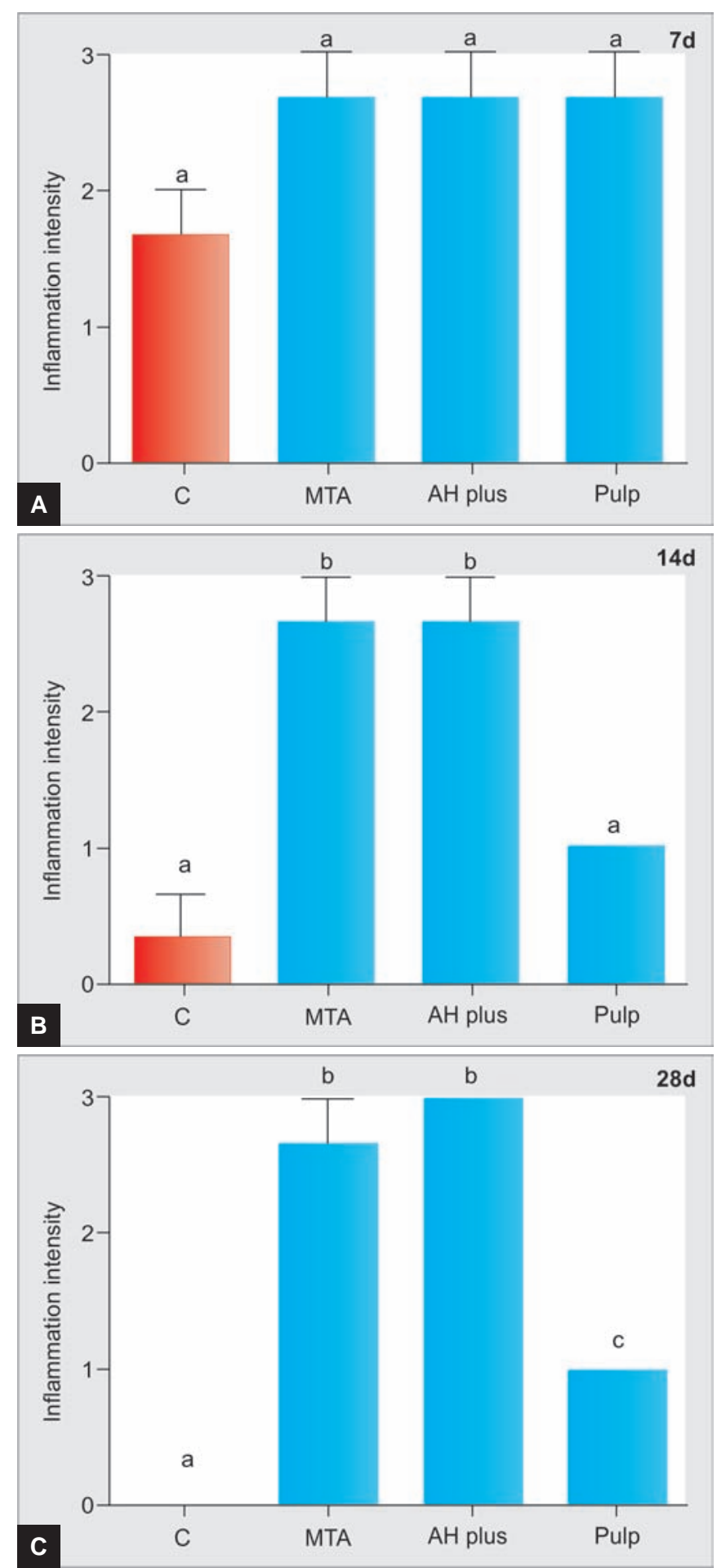

Graphs 1A to C: Results of the histological score analysis of the inflammatory reaction to the materials tested, as compared with the control (bone defects without material), 7 days (A) 14 days; (B) 28 days; and $(C)$ after surgery. Same letters indicate no significant statistical difference $(p>0.05)$ between the tested sealers and the control

as adequate for the evaluation of tissue reactions in animal models, which is an indispensable step to complete material examination. ${ }^{1,2,5}$ In the present study, it was demonstrated that this method is also able to identify differences on compatibility between members of diverse groups of sealers. The bone tissue response model can simulate to the clinical application of those materials. ${ }^{8}$

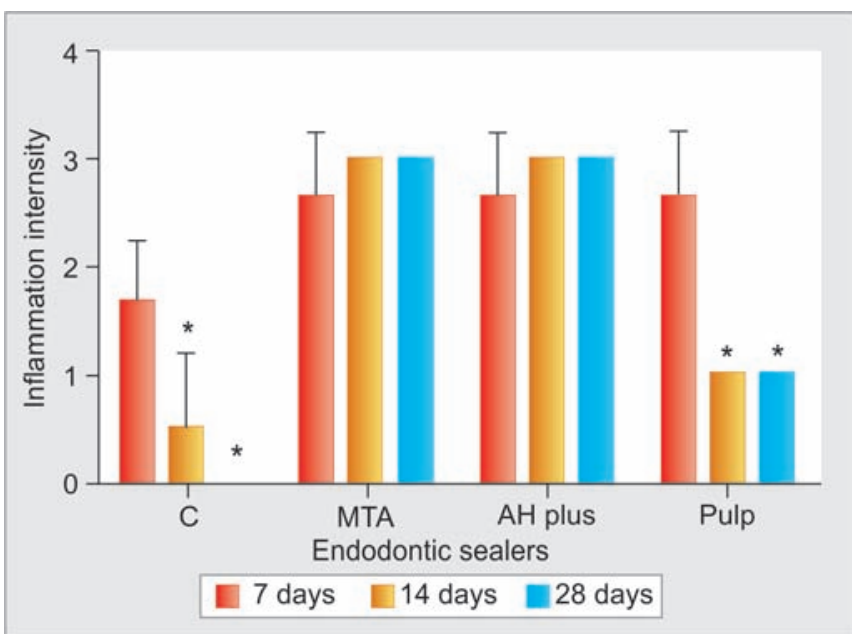

Graph 2: Results of the intragroup histological score analysis of the inflammatory reaction to the materials tested. The symbol * indicates statistical significance in comparison to day 7 in the group analyzed $(p<0.05)$

Regarding studies of biocompatibility, it is also important to consider the inherent characteristics and possible interpretations of the results associated with the experimental model employed. The diffusion of substances through live periapical tissues, for instance, may be rather different than the release and diffusion on the cell culture media employed on in vitro assays, and often cells are more susceptible to noxious effects. ${ }^{8}$ In addition, protein molecules that participate in the fluid phase and extracellular matrix of tissues, as well as phagocyte cells, blood, and lymphatic systems, may decrease the cytotoxic effect of some released substances. ${ }^{17}$ In this context, a bone defect model might be adequate to assess the inflammatory response expected on this kind of tissue, considering even the effects of material movement.

In the 1st week after grafting, both control and test groups presented considerable levels of inflammatory response (Figs 1A to D), a phenomenon which could be already observed 24 hours after grafting (data not shown). It is very possible, therefore, that this response can be associated with surgical trauma, rather than caused by the material toxicity.

The cytotoxic behavior that seemed to remain in longer period of time for AH Plus, which is an epoxybased resin material, ${ }^{18}$ is coherent with the reactivity of silorane resins that have been used in the formulation of some dental composites and have a similar resin chemical composition. ${ }^{19}$ The comparable cytotoxic behavior of $\mathrm{AH}$ Plus and epoxies suggests that a parallel corrosion processes may be occurring when the materials are placed in biological contexts. ${ }^{20}$ On the other hand, the shortterm cytotoxicity of AH Plus has also been attributed to a minute release of formaldehyde, which decreases after setting. ${ }^{21}$ Probably, it was this reason that previous in vivo studies have report severe reactions to this material. ${ }^{22}$ 
In the present study, MTA Fillapex, a bioceramic sealer, showed high levels of inflammatory response 28 days after grafting. This material was created based on a calcium silicate composition, in an attempt to combine the physicochemical properties of a root canal sealer with the biological properties of MTA. The setting and hardening of this sealer occurs by a complex reaction between the calcium ions present in the catalyst paste and the disalicylate present in the base paste. The literature has demonstrated that MTA Fillapex strongly affects primary human cell viability up to 7 days after setting. ${ }^{8}$ In addition, Bin et $\mathrm{al}^{23}$ have identified a strong genotoxicity for this material.

Currently, there are two other MTA-based or bioceramic sealers commercially available: Endo-CPMSealer (EGEO S.R.L., Buenos Aires, Argentina) and IRoot SP (Innovative BioCeramix, Inc., Vancouver, CA). Both sealers had presented good preliminary results on biocompatibility tests and differ chemically from MTA Fillapex, including the absence of salicylate in their composition. ${ }^{24,25}$ In fact, there are evidences indicating a potential toxicity for salicylate-containing materials. A previous study evaluating the effect of resin salicylate on human fibrosarcoma cell line (HT-1080) showed a direct correlation between salicylate concentration and cell death rate. ${ }^{26}$

Pulp Canal Sealer EWT showed the lowest inflammatory response when compared with MTA Fillapex and AH Plus, as it decreased from 14 to 28 days. This favorable result for Pulp Canal Sealer does not agree with a previous in vitro report, showing that standard Pulp Canal Sealer remained severely cytotoxic throughout a 6-weeks conditioned-media assay. ${ }^{9}$ Such cytotoxicity could be due to the continuous elution of eugenol, which could also act as a potential source of irritation when this sealer is inadvertently extruded through the apical foramen into the periapical tissues. ${ }^{27}$ On the other hand, a recent study employing primary human osteoblasts conducted by Scelza et $\mathrm{al}^{8}$ demonstrated that even in longer setting period (7 days), Pulp Canal Sealer EWT can show high levels of cytocompatibility. It is relevant to note that standard Pulp Canal Sealer and Pulp Canal Sealer EWT have differences in their composition: Pulp Canal Sealer EWT does not contain thymol iodine, which may provide a possible explanation for the lower cytotoxicity observed for the EWT. Further studies are required to evaluate the influence of thymol iodine over cytotoxicity.

The present study has shown that the bone defect model is adequate to identify differences on the tissue response to endodontic sealers. However, further in vivo research efforts are required to completely validate the potential and predictability of clinical outcome provided by the method.

\section{CONCLUSION}

MTA Fillapex, Pulp Canal Sealer EWT, and AH Plus elicited different levels of inflammatory response when their biocompatibility was tested through an in vivo murine bone defect grafting model, after a 28-day period. Pulp Canal Sealer EWT demonstrated high levels of biocompatibility and the parameters for inflammatory response decreased with time. The critical defect grafting model was an effective method to detect differences on the biological response to endodontic sealers.

\section{CLINICAL SIGNIFICANCE}

Knowing the biocompatibility of endodontics sealers that will be used in filling the root canal.

\section{ACKNOWLEDGMENT}

Authors would like to express their appreciation to Carolina Santana Ferreira and Laís Barbosa for helping during the surgery.

\section{REFERENCES}

1. Ogasawara T, Yoshimine $\mathrm{Y}$, Yamamoto M, Akamine A. Biocompatibility of an experimental glass-ionomer cement sealer in rat mandibular bone. Oral Surg Oral Med Oral Pathol Oral Radiol Endod 2003 Oct;96(4):458-465.

2. Al-Hiyasat AS, Tayyar M, Darmani H. Cytotoxicity evaluation of various resin based root canal sealers. Int Endod J 2010 Feb;43(2):148-153.

3. Orstavik D. Materials used for root canal obturation: technical, biological and clinical testing. Endod Topics 2005 Nov;12(1):25-38.

4. ASTM International Standard Practice for Direct Contact Cell Culture Evaluation of Materials for Medical Devices. ASTM Standard Test Method F 0813-07 ed. 2007.

5. International Organization for Standardization ISO 7405: 2008. Dentistry - Preclinical evaluation of biocompatibility of medical devices used in dentistry - Test methods for dental materials. ISO 7405:2008; 2008.

6. International Organization for Standardization ISO 10993-1. Biological evaluation of medical devices - Part 1: evaluation and testing within a risk management process. ISO 10993-1 ed.; 2009.

7. Zhang H, Shen Y, Ruse ND, Haapasalo M. Antibacterial activity of endodontic sealers by modified direct contact test against Enterococcus faecalis. J Endod 2009 Jul; 35(7): 1051-1055.

8. Scelza MZ, Linhares AB, da Silva LE, Granjeiro JM, Alves GG. A multiparametric assay to compare the cytotoxicity of endodontic sealers with primary human osteoblasts. Int Endod J 2012 Jan;45(1):12-18.

9. Bryan TE, Khechen K, Brackett MG, Messer RL, El-Awady A, Primus CM, Gutmann JL, Tay FR. In vitro osteogenic potential of an experimental calcium silicate-based root canal sealer. J Endod 2010 Jul;36(7):1163-1169.

10. De Deus G, Ximenes R, Gurgel-Filho ED, Plotkowski MC, Coutinho-Filho T. Cytotoxicity of MTA and Portland cement 
on human ECV 304 endothelial cells. Int Endod J 2005 Sep;38(9):604-609.

11. Seltzer S. Long-term radiographic and histological observations of endodontically treated teeth. J Endod 1999 Dec; 25(12):818-822.

12. International Organization for Standardization ISO 10993-6. Biological evaluation of medical devices - Part 6: tests for local effects after implantation. ISO 10993-6 ed.; 2007.

13. Scelza MFZ, da Silva Pierro V, Chagas MA, da Silva LE, Scelza P. Evaluation of inflammatory response of EDTA, EDTA-T, and citric acid in animal model. J Endod 2010 Mar;36(3): 515-519.

14. Schmitz JP, Hollinger JO. The critical size defect as an experimental model for craniomandibulofacial nonunions. Clin Orthop Relat Res 1986 Apr;(205):299-308.

15. Furuse C, Miguita L, Rosa AC, Soares AB, Martinez EF, Altemani A, de Araújo VC. Study of growth factors and receptors in carcinoma ex pleomorphic adenoma. J Oral Pathol Med 2010 Aug;39(7):540-547.

16. Soares AB, Demasi AP, Altemani A, de Araújo VC. Increased mucin 1 expression in recurrence and malignant transformation of salivary gland pleomorphic adenoma. Histopathology 2011 Feb;58(3):377-382.

17. Scelza MFZ, Lima Oliveira LR, Carvalho FB, Corte-Real FS. In vitro evaluation of macrophage viability after incubation in orange oil, eucalyptol, and chloroform. Oral Surg Oral Med Oral Pathol Oral Radiol Endod 2006 Sep;102(3): e24-e27.

18. Brackett MG, Marshall A, Lockwood PE, Lewis JB, Messer RL, Bouillaguet S, Wataha JC. Cytotoxicity of endodontic materials over 6-weeks ex vivo. Int Endod J 2008 Dec;41(12):1072-1078.
19. Eick JD, Smith RE, Pinzino CS, Kostoryz EL. Stability of silorane dental monomers in aqueous systems. J Dent 2006 Jul;34(6):405-410.

20. Geurtsen W, Leyhausen G. Biological aspects of root canal filling materials - histocompatibility, cytotoxicity, and mutagenicity. Clin Oral Investig 1997 Mar;1(1):5-11.

21. Leonardo MR, Bezerra da Silva LA, Filho MT, Santana da Silva R. Release of formaldehyde by 4 endodontic sealers. Oral Surg Oral Med Oral Pathol Oral Radiol Endod 1999 Aug;88(2):221-225.

22. Sousa CJ, Montes CR, Pascon EA, Loyola AM, Versiani MA. Comparison of the intraosseous biocompatibility of $\mathrm{AH}$ Plus, EndoREZ, and Epiphany root canal sealers. J Endod 2006 Jul;32(7):656-662.

23. Bin CV, Valera MC, CamargoSE, RabeloSB, Silva GO, Balducci I, Camargo $\mathrm{CH}$. Cytotoxicity and genotoxicity of root canal sealers based on mineral trioxide aggregate. J Endod 2012 Apr;38(4):495-500.

24. De-Deus G, Canabarro A, Alves GG, Marins JR, Linhares $\mathrm{AB}$, Granjeiro JM. Cytocompatibility of the ready-to-use bioceramic putty repair cement iRoot BP Plus with primary human osteoblasts. Int Endod J 2012 Jun;45(6):508-513.

25. Scarparo RK, Haddad D, Acasigua GA, Fossati AC, Fachin EV, Grecca FS. Mineral trioxide aggregate-based sealer: analysis of tissue reactions to a new endodontic material. J Endod 2010 Jul;36(7):1174-1178.

26. Mahdi JG, Alkarrawi MA, Mahdi AJ, Bowen ID, Humam D. Calcium salicylate-mediated apoptosis in human HT-1080 fibrosarcoma cells. Cell Prolif 2006 Aug;39(4):249-260.

27. Dahl JE. Toxicity of endodontic filling materials. Endod Topics 2005 Nov;12(1):39-43. 